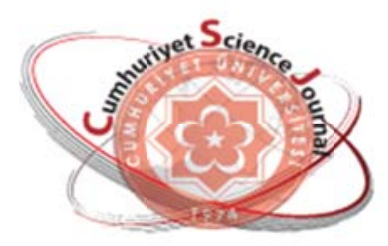

e-ISSN: $2587-246 X$

ISSN: 2587-2680

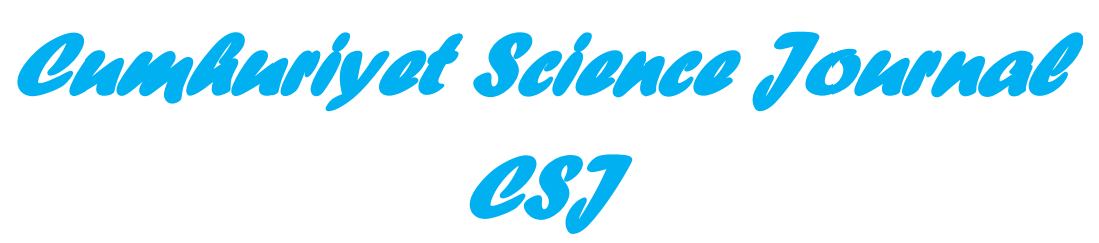

Cumhuriyet Sci. J., Vol.40-2 (2019) 378-387

\title{
APT-Pareto Distribution and its Properties
}

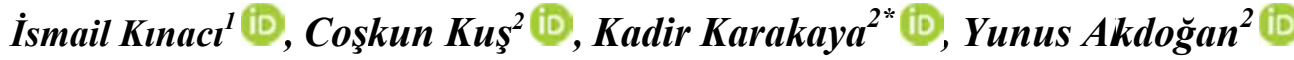 \\ ${ }^{1}$ Department of Actuarial Sciences, Selçuk University, 42250, Konya, TURKEY \\ ${ }^{2}$ Department of Statistics, Selçuk University, 42250, Konya, TUR'KEY
}

\begin{abstract}
Recently, the APT-family has been introduced as a new family of distributions. A special case of this family with exponential distribution is examined in details. In this paper, Pareto is considered as a baseline distribution in APT-family. Several properties of the APT-Pareto distribution such as the moments, hazard rate and survival functions are derived. The maximum likelihood and least square methods are discussed. Simulation study is also performed to get the bias and mean square errors of estimates. A numerical example is given to illustrate the capability of APT-Pareto distribution for modelling real data.
\end{abstract}

Keywords: Distribution family, Estimation, Pareto distribution, Simulation.

\section{APT-Pareto Dağılımı ve Özellikleri}

Özet. Son zamanlarda, APT-dağılım ailesi adında yeni bir dağılım ailesi tanıtılııştır. Bu dağılım ailesi için üstel dağılım durumunu detaylı bir şekilde ele alınmıştır. Bu makalede, APT-dağılım ailesinde Pareto dağılımı çalışılmıştır. APT-Pareto dağılımına ilişkin momentler, hazard fonksiyonu, yaşam fonksiyonu gibi özellikleri elde edilmiştir. En çok olabilirlik ve en küçük kareler yöntemleri tartışılmıştır. Tahmin edicilerin yan ve hata kareler ortalamalarını elde edebilmek için simülasyon çalışması yapılmıştır. AP'T-Pareto dağılımının modellemedeki kullanılabilirliğini göstermek amacıyla gerçek bir veri uygulaması yapıllmıştır.

Anahtar Kelimeler: Dağılımlar ailesi, Tahmin, Pareto dağılımı, Simülasyon

\section{INTRODUCTION}

Distribution theory is one of the most important areas of statistics. In the last two decades, there are too many statistical distributions are introduced by including an extra parameter to an existing family of distribution functions. Azzalini [1] introduced the skew normal distribution by adding an extra parameter $\lambda$ to the normal distribution. Let $Z$ be the skew-normal random variable, then the density function of $Z$ is of

$$
\phi(z ; \lambda)=2 \phi(z) \Phi(\lambda z), z \in \mathbb{R},
$$

where $\phi$ and $\Phi$ are the standard normal density and distribution function, respectively. It is clear that the skew-normal distribution is reduced standard normal distribution for $\lambda=0$.

\footnotetext{
* Corresponding author. Email address: kkarakaya@selcuk.edu.tr

http://dergipark.gov.tr/csj $\quad$ C2016 Faculty of Science, Sivas Cumhuriyet University
} 
Mudholkar and Srivastava [2] proposed a method to include an extra parameter to a two-parameter Weibull distribution. If a random variable $Z$ has distribution function $F(z)$, then $(F(z))^{\theta}$ $(\theta>0)$ is also distribution function and it is called exponentiated family, where $F(z)$, is baseline distribution. Mudholkar and Srivastava [2] considered $F(z)=\left(1-\exp (-z / \sigma)^{\alpha}\right)$ as a baseline distribution and they get the distribution with cdf

$$
F(z)=\left(1-\exp (-z / \sigma)^{\alpha}\right)^{\theta}
$$

and called it as exponentiated-Weibull family, where $\theta$ is an extra parameter. Some exponentiated distributions have been introduced by several authors, see for example Gupta et al. [3], Gupta and Kundu [4] and etc.

Marshall and Olkin [5] proposed another method to introduce an additional parameter to any distribution function as follows. Let $Z$ is a random variable with cdf $F$ and density $f$, then

$$
g(z)=\frac{\alpha f(z)}{\{1-(1-\alpha)(1-F(z))\}^{2}}
$$

is also pdf of a random variable, where $\alpha$ is an extra parameter. Marshall and Olkin [5] cosidered exponential and Weibull distribution for baseline distribution $f(z)$.

Eugene et al. [6] proposed the beta generated method which is defined as follows: Let $Z$ is a random variable with cdf $F$, then

$$
G(z)=\frac{\Gamma(\alpha+\beta)}{\Gamma(\alpha) \Gamma(\beta)} \int_{0}^{F(z)} t^{\alpha-1}(1-t)^{\beta-1} d t
$$

is a distribution function as well, where $(\alpha, \beta) \in \mathbb{R}_{+}^{2}$ is an extra parameter vector.

Alzaatreh et al. [7] introduced a new method for generating families of continuous distributions called T-X family using same idea of Eugene et al. [6]

Mahdavi and Kundu [8] introduced an extra parameter to a family of distributions functions to bring more flexibility to the given family. This new method is called $\alpha$-power transformation (APT) method. The proposed APT method is very easy to use, hence it can be used extensively for the data modelling purposes. The pdf and cdf of APT-family are given, respectively, by

$$
f_{A P T}(x)=\left\{\begin{array}{cc}
\frac{\log (\alpha)}{\alpha-1} f(x) \alpha^{F(x)} I_{A}(x) & , \quad \alpha \neq 1 \\
f(x) & , \quad \alpha=1
\end{array}\right.
$$

and

$$
F_{A P T}(x)=\left\{\begin{array}{cc}
\frac{\alpha^{F(x)}-1}{\alpha-1} I_{A}(x) & , \quad \alpha \neq 1 \\
F(x) & , \quad \alpha=1,
\end{array}\right.
$$

where $\alpha>0$ is an extra parameter and $I_{A}(x)$ is indicator function on set $A$ which is domain of baseline distribution. Mahdavi and Kundu [8] applied the $\alpha$-power transformation to exponential 
distribution.

An extra parameter supplies more flexibility to a class of distribution functions and it can be very useful for the data analysis. It should be point out that the adding extra parameter caused the estimation problem, but it can be solved by numerical methods. $\mathrm{R}$ and Matlab have several numerical algorithms for this job.

In this paper, $\alpha$-power transformation is applied to Pareto distribution. In Section 2, moments, hazard rate and survival functions are given. The maximum likelihood and least square methods are discussed in Section 3. In Section 4, a simulation study is also performed to observe the performance of the estimates. A numerical example with the real data is given to illustrate the flexibility of APT-Pareto distribution for modelling real data in Section 5.

\section{2. $\alpha$-POWER PARETO DISTRIBUTION}

In this paper, Pareto distribution is considered. The pdf and cdf of the Pareto distribution are given, respectively, by

$$
f_{p}(x)=\beta x^{-\beta-1} I(1, \infty)
$$

and

$$
F_{p}(x)=1-x^{-\beta} I(1, \infty)
$$

where $\beta>0$ is a shape parameter and $I_{A}($.$) is indicator function.$

Using Eqs. (3)-(4) in Eqs. (1)-(2), the pdf and cdf of APT-Pareto distribution are defined by

$$
f_{\text {APTP }}(x)=\left\{\begin{array}{cc}
\frac{\log (\alpha)}{\alpha-1} \beta x^{-\beta-1} \alpha^{1-x^{-\beta}} I_{(1, \infty)}(x) & , \alpha \neq 1, \\
\beta x^{-\beta-1} & , \quad \alpha=1
\end{array}\right.
$$

and

$$
F_{A P T P}(x)=\left\{\begin{array}{cc}
\frac{\alpha^{\left(1-x^{-\beta}\right)}-1}{\alpha-1} I_{(1, \infty)}(x) & , \quad \alpha \neq 1 \\
\left(1-x^{-\beta}\right) & , \quad \alpha=1,
\end{array}\right.
$$

respectively. The random variable $X$ is said to have a two-parameter APT-Pareto distribution and it is denoted by $\operatorname{APTP}(\alpha, \beta)$.

Fig. 1 presents the plots pdf of $\operatorname{APTP}(\alpha, \beta)$ for some choices of $\alpha$ and $\beta$. 

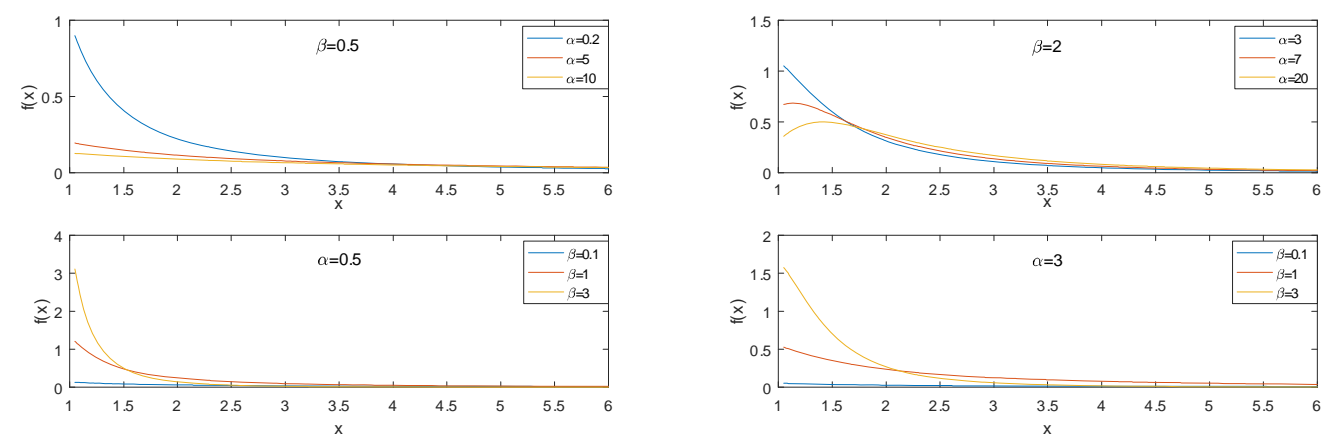

Figure 1. Pdf of APTP distribution for some choices of $\alpha$ and $\beta$

In the rest of paper, the case $\alpha \neq 1$ is only considered. The survival function and the hazard rate function for APTP distribution are given in the following forms

$$
S_{A P T P}(x)=\frac{\alpha-\alpha^{\left(1-x^{-\beta}\right)}}{\alpha-1}
$$

and

$$
h_{A P T P}(x)=\frac{\log (\alpha) \beta x^{-\beta-1} \alpha^{1-x^{-\beta}}}{\left.\alpha-\alpha^{\left(1-x^{-\beta}\right.}\right)},
$$

respectively. Fig. 2 presents the plots the hazard rate function of $\operatorname{APTP}(\alpha, \beta)$ for some choices of $\alpha$ and $\beta$.
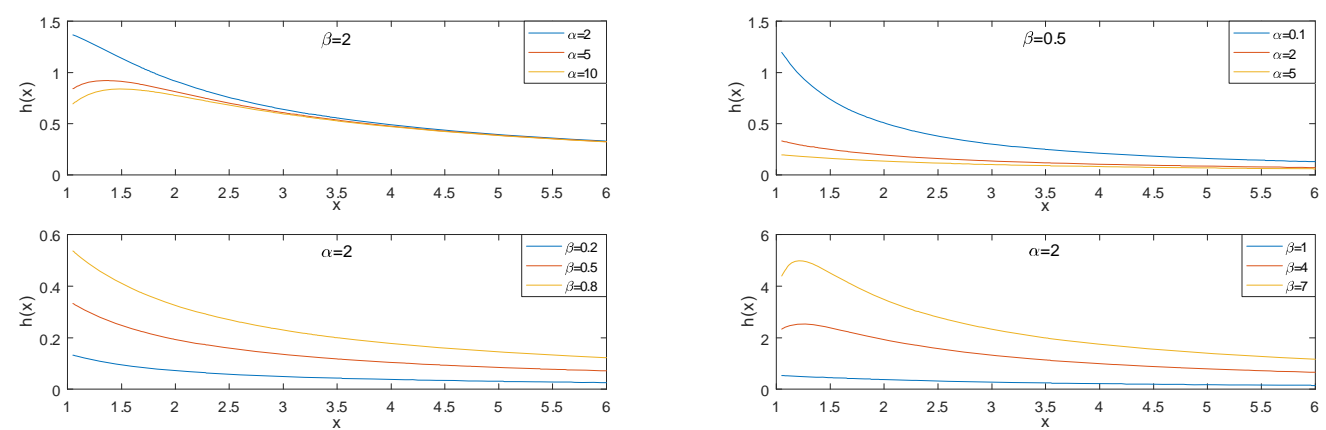

Figure 2. Hazard rate function of APTP distribution for some choices of $\alpha$ and $\beta$

The $r$ th moment of APTP distribution is obtained by

$$
\begin{aligned}
E\left(X^{r}\right)= & \int_{1}^{\infty} x^{r} \frac{\log (\alpha)}{\alpha-1} \beta x^{-\beta-1} \alpha^{1-x^{-\beta}} d x \\
= & \frac{\log (\alpha)}{1-\alpha} \alpha \beta \sum_{i=0}^{\infty}(-1)^{i} \frac{\log (\alpha)^{i}}{i !}\left(\frac{1}{r-\beta(i+1)}\right) . \\
= & \frac{\log (\alpha)^{\left(\frac{r-2 \beta}{2 \beta}\right)} \beta \sqrt{a}\left((r-2 \beta)^{2} \text { WhittakerM }\left(\frac{-r+2 \beta}{2 \beta}, \frac{-r+3 \beta}{2 \beta}, \log (\alpha)\right)\right)}{(r-2 \beta)(r-3 \beta)(\alpha-1)(\beta-r)} \\
& -\frac{\log (\alpha)^{\left(\frac{1-2 \beta}{2 \beta}\right)} \beta \sqrt{a}\left(\beta \text { WhittakerM }\left(\frac{-r}{2 \beta}, \frac{-r+3 \beta}{2 \beta}, \log (\alpha)\right)(r-\log (\alpha) \beta-2 \beta)\right)}{(r-2 \beta)(r-3 \beta)(\alpha-1)(\beta-r)},
\end{aligned}
$$


where the WhittakerM( $a, b, c)$ is a Whittaker function and it can be easily calculated by Maple or Matlab. It should be noted that $r$ th moments works for only $\beta>\frac{3}{2} r$. This restriction has been observed in simulation study. It is not proved here.

Moment generating function of APTP distribution is given by

$$
\begin{aligned}
M_{X}(t) & =\int_{1}^{\infty} \exp (t x) \frac{\log (\alpha)}{\alpha-1} \beta x^{-\beta-1} \alpha^{1-x^{-\beta}} d x \\
& =\frac{\log (\alpha) \beta \alpha}{\alpha-1} \sum_{i=0}^{\infty} \frac{(-t)^{\beta(i+1)}(-\log (\alpha))^{i} \Gamma(-\beta(i+1),-t)}{i !}
\end{aligned}
$$

where $\Gamma(a, b)$ is the incomplete gamma function.

\section{ESTIMATION}

\subsection{Maximum-Likelihood Method}

Let $X_{1}, X_{2}, \ldots, X_{n}$ be a random sample from $\operatorname{APTP}(\alpha, \beta)$, then $\log$-likelihood function is given by

$$
\ell(\alpha, \beta)=n \log \left(\frac{\log (\alpha)}{\alpha-1}\right)+n \log (\beta)-(\beta+1) \sum_{i=1}^{n} \log \left(x_{i}\right)+\left(n-\sum_{i=1}^{n} x_{i}^{\beta}\right) \log (\alpha) .
$$

The likelihood equations are found to be

$$
\begin{aligned}
& \frac{\partial \ell(\alpha, \beta)}{\partial \alpha}=n\left(\frac{\alpha-1}{\log (\alpha)}\right)\left(\frac{1}{\alpha(\alpha-1)}-\frac{\log (\alpha)}{(\alpha-1)^{2}}\right)+\frac{n-\sum_{i=1}^{n} x_{i}^{\beta}}{\alpha}=0, \\
& \frac{\partial \ell(\alpha, \beta)}{\partial \beta}=\frac{n}{\beta}-\sum_{i=1}^{n} \log \left(x_{i}\right)-\log (\alpha) \sum_{i=1}^{n} x_{i}^{\beta} \log \left(x_{i}\right)=0 .
\end{aligned}
$$

Maximum likelihood estimates (MLE) of $\alpha$ and $\beta$ are obtained by solving likelihood equations. The likelihood equations cannot be solved explicitly. Likelihood function can be maximized by numerical method. fminsearch MATLAB command can be used for this job. fminsearch uses the simplex search method of Lagarias et al. [9].

\subsection{Least-squares Method}

Let $x_{(1)}<x_{(2)}<\cdots<x_{(n)}$ denote the ordered observations from $\operatorname{APTP}(\alpha, \beta)$ distribution. Using the distribution function given in Eq. (6), we can write

$$
F\left(x_{(i)}\right)=\frac{\alpha^{\left(1-x_{(i)}^{-\beta}\right)}-1}{\alpha-1}, \quad i=1,2, \ldots, n
$$

Empirical distribution function, denoted by $F^{*}$ can be used to estimate $F\left(x_{(i)}\right)$ in (7). Substituting the empirical distribution function in Eq. (7), we have the following model: 


$$
F^{*}\left(x_{(i)}\right)=\frac{\alpha^{\left(1-x_{(i)}^{-\beta}\right)}-1}{\alpha-1}+\varepsilon_{i}, \quad i=1,2, \ldots, n,
$$

where $\varepsilon_{i}$ is the error term for $i$ th observation. Now, the least squares estimators $(\tilde{\alpha}, \tilde{\beta})$ of parameters can be obtained by minimizing the following equation with respect to $\alpha$ and $\beta$ :

$$
L(\alpha, \beta)=\sum_{i=1}^{n} \varepsilon_{i}^{2}=\sum_{i=1}^{n}\left(F^{*}\left(x_{(i)}\right)-\frac{\alpha^{\left(1-x_{(i)}^{-\beta}\right)}-1}{\alpha-1}\right)^{2}, \quad i=1,2, \ldots, n .
$$

Least-squares estimates (LSE) of $\alpha$ and $\beta$ can be obtained by numerical methods. fminsearch MATLAB command can be used for this job.

\section{SIMULATION STUDY}

In this section, a simulation study is conducted to compare the ability of estimation procedures discussed in the previous section. In the simulation, $X_{1}, X_{2}, \ldots, X_{n}$ from the APTP distribution are generated and then computed the MLEs and LSEs of $\alpha$ and $\beta$ with 10000 repetitions. We then compared the performance of these estimates in terms of their biases and mean square errors (MSE). We reported the biases and MSEs of these estimates in Tables 1-2, for different values of $n$ and $(\alpha, \beta)$.

From Tables 1-2, it is observed that both estimates are biased but asymptotically unbiased. Also, as the sample size $n$ increases, the bias and MSEs of the estimators decreases as expected.

Table 1: Bias of MLEs and LSEs for some parameter values of $\alpha$ and $\beta$

\begin{tabular}{ccccccc}
\hline$\alpha$ & $\beta$ & $n$ & $\hat{\alpha}$ & $\hat{\beta}$ & $\tilde{\alpha}$ & $\tilde{\beta}$ \\
\hline 2 & 2 & 50 & 1.3612 & 0.0939 & 1.5310 & 0.1023 \\
& & 100 & 0.5514 & 0.0420 & 0.5679 & 0.0413 \\
& & 200 & 0.2525 & 0.0196 & 0.2718 & 0.0226 \\
& & 300 & 0.1734 & 0.0146 & 0.1764 & 0.0151 \\
& & 400 & 0.1341 & 0.0120 & 0.1395 & 0.0137 \\
& & 500 & 0.1031 & 0.0094 & 0.1053 & 0.0102 \\
3 & 1 & 50 & 2.1219 & 0.0398 & 2.4204 & 0.0439 \\
& & 100 & 0.8103 & 0.0178 & 0.8230 & 0.0196 \\
& & 200 & 0.3690 & 0.0085 & 0.3904 & 0.0107 \\
& & 300 & 0.2532 & 0.0063 & 0.2573 & 0.0071 \\
& & 400 & 0.1809 & 0.0044 & 0.1837 & 0.0050 \\
& & 500 & 0.1532 & 0.0043 & 0.1553 & 0.0051 \\
0.5 & 0.8 & 50 & 0.4662 & 0.0908 & 0.6711 & 0.1070 \\
& & & & & & \\
& & 200 & 0.1950 & 0.0402 & 0.2800 & 0.0435 \\
& & & 0.0912 & 0.0173 & 0.1241 & 0.0131 \\
& & & & & \\
& & 0.0620 & 0.0109 & 0.0849 & 0.0073 \\
& & 500 & 0.0477 & 0.0088 & 0.0648 & 0.0059 \\
& & & & & & \\
\hline
\end{tabular}


Table 2: MSEs of MLEs and LSEs for some parameter values of $\alpha$ and $\beta$

\begin{tabular}{ccccccc}
\hline$\alpha$ & $\beta$ & $n$ & $\hat{\alpha}$ & $\hat{\beta}$ & $\tilde{\alpha}$ & $\tilde{\beta}$ \\
\hline 2 & 2 & 50 & 21.6056 & 0.2314 & 29.8067 & 0.3724 \\
& & 100 & 3.4502 & 0.1083 & 4.4688 & 0.1694 \\
& & 200 & 1.1274 & 0.0540 & 1.5549 & 0.0812 \\
& 300 & 0.6866 & 0.0365 & 0.9176 & 0.0556 \\
& 400 & 0.4863 & 0.0269 & 0.6272 & 0.0398 \\
& & 500 & 0.3657 & 0.0213 & 0.4724 & 0.0318 \\
& & & & & & \\
3 & 1 & 50 & 46.9261 & 0.0463 & 165.8959 & 0.0686 \\
& & 100 & 7.6548 & 0.0221 & 9.6245 & 0.0322 \\
& 200 & 2.4231 & 0.0109 & 3.2240 & 0.0154 \\
& 300 & 1.4694 & 0.0074 & 1.8830 & 0.0106 \\
& 400 & 1.0050 & 0.0055 & 1.2791 & 0.0076 \\
& 500 & 0.7841 & 0.0043 & 0.9722 & 0.0061 \\
& & & & & \\
& & & & & & \\
0.5 & 0.8 & 50 & 1.9843 & 0.0835 & 4.0642 & 0.1515 \\
& & 100 & 0.4171 & 0.0446 & 0.7355 & 0.0797 \\
& 200 & 0.1338 & 0.0224 & 0.2367 & 0.0439 \\
& 300 & 0.0818 & 0.0152 & 0.1480 & 0.0312 \\
& 400 & 0.0564 & 0.0114 & 0.1050 & 0.0243 \\
& 500 & 0.0430 & 0.0088 & 0.0788 & 0.0190 \\
& & & & &
\end{tabular}

\section{REAL DATA ANALYSIS}

In this section, we illustrate the ability of the APTP distribution. We fit this distribution to two real data sets and compare the results with the distributions in the literature. In order to compare the models, we used following three criterions: Akaike Information Criterion(AIC), Bayesian Information Criterion (BIC) and log-likelihood $(\ell)$ values, where the lower values of AIC, BIC and the upper value of $\ell$ values for models indicate that these models could be chosen as the best model to fit the data sets.

First real data: First real data set is given in Feigl and Zelen [10] for the patients who died of acute myelogenous leukemia. Feigl and Zelen [10] represent observed survival times (weeks) for AG negative. The data set is: $56,65,17,17,16,22,3,4,2,3,8,4,3,30,4,43$. APTP, Weibull, AlphaPower Exponential( Mahdavi and Kundu [8]), Exponentiated Exponential (Gupta and Kundu, [3]), Beta Generalized-Exponential (BGE) (Barreto-Souza et al. [11]), Beta-Exponential (BE) (Nadarajah and Kotz [12]), Beta-Pareto (BP)(Akinsete et al. [13]), Generalized Exponential (GE)(Gupta and Kundu [14]), Exponential Poisson (EP) (Kus [15]), Beta Generalized Half-Normal (BGHN) (Pescim et al. [16]), Generalized Half-Normal (GHN)(Cooray and Ananda [17]) and Gamma-Uniform (GU) (Torabi 
and Montazeri [18]) distributions are fitted to data. Table 3 shows that the APTP distribution gives a better fit than the other models for all criteria except GU distribution.

Table 3. Results of AIC, BIC and log-likelihood for APTP and other distributions for the data set

\begin{tabular}{|l|l|c|c|c|}
\hline Model & ML Estimates of Parameters & AIC & BIC & $\ell$ \\
\hline APTP & $\hat{\alpha}=485.771, \hat{\beta}=1.034$ & 127.3 & 128.9 & -61.6 \\
\hline Pareto & $\hat{\alpha}=0.431$ & 135.2 & 135.9 & -66.6 \\
\hline BGHN & $\hat{a}=0.09, \hat{b}=0.40, \hat{\alpha}=5.99, \hat{\theta}=132.49$ & 131.9 & 134.9 & -61.9 \\
\hline GHN & $\hat{\alpha}=0.76, \hat{\theta}=73.62$ & 130.2 & 131.8 & -63.1 \\
\hline GE & $\hat{\alpha}=0.757, \hat{\theta}=0.013$ & 129.5 & 131 & -62.7 \\
\hline EP & $\hat{\alpha}=0.01, \hat{\theta}=0.016$ & 129.1 & 130.6 & -62.5 \\
\hline BP & $\hat{a}=20.35, \hat{b}=32.71, \hat{\alpha}=0.01, \hat{\theta}=0.06$ & 129.7 & 132.8 & -62.8 \\
\hline Weibull & $\hat{\alpha}=0.948, \hat{\beta}=0.055$ & 129.4 & 130.9 & -62.6 \\
\hline EE & $\hat{\alpha}=0.968, \hat{\theta}=0.053$ & 129.5 & 131.0 & -62.7 \\
\hline APE & $\hat{\alpha}=0.364, \hat{\beta}=0.042$ & 129.1 & 130.6 & -62.5 \\
\hline BGE & $\hat{a}=37.95, \hat{b}=3.33, \hat{\alpha}=0.013, \hat{\theta}=0.04$ & 132.9 & 135.9 & -62.4 \\
\hline BE & $\hat{b}=2.998, \hat{\alpha}=0.96, \hat{\theta}=0.017$ & 131.5 & 133.8 & -62.7 \\
\hline GU & $\hat{a}=1.99, \hat{b}=165.39, \hat{\alpha}=0.46, \hat{\theta}=0.30$ & 126.1 & -57.5 \\
\hline
\end{tabular}

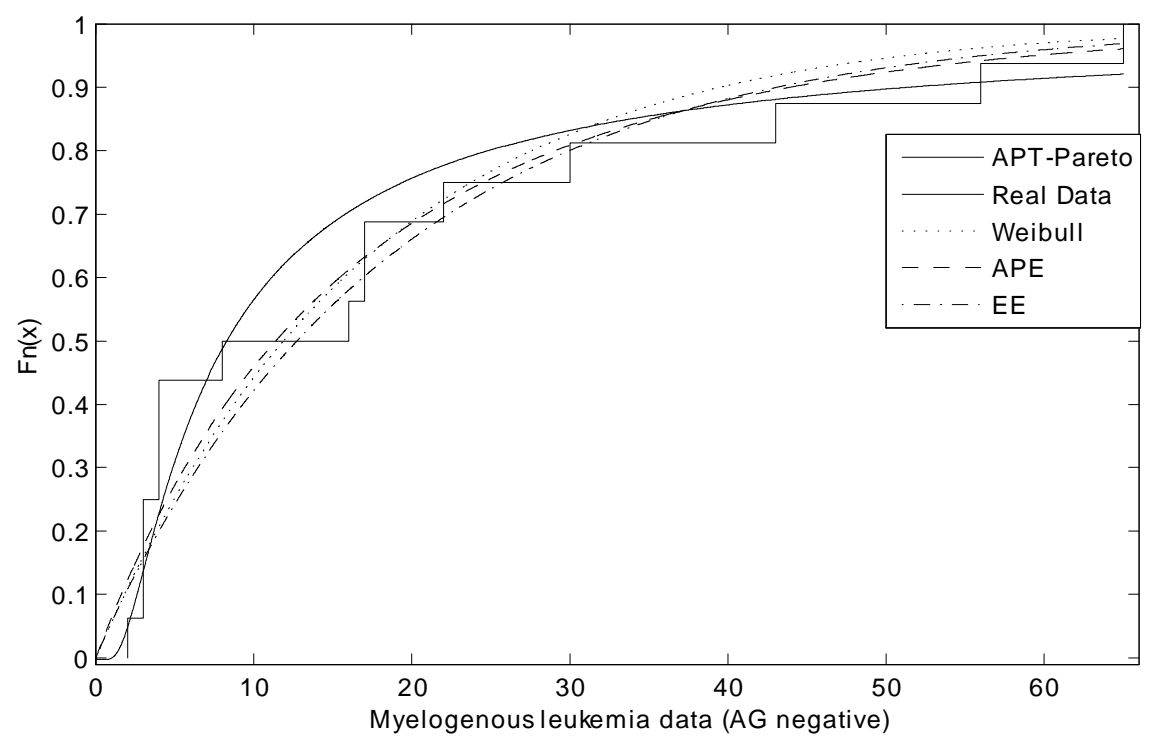

Figure 3. Empirical and some fitted distribution functions based on myelogenous leukemia data

Second real data set: The real dataset is taken from Nassar and Nada [19], which gives the relief times of 32 patients receiving an analgesic. The data are: 5.9, 20.4, 14.9, 16.2, 17.2, 7.8, 6.1, 9.2, 10.2, 9.6, 13.3, 8.5, 21.6, 18.5, 5.1,6.7, 17, 8.6, 9.7, 39.2, 35.7, 15.7, 9.7, 10, 4.1, 36, 8.5, 8, 9.2, 26.2, 21.9,16.7, $21.3,35.4,14.3,8.5,10.6,19.1,20.5,7.1,7.7,18.1,16.5,11.9,7,8.6,12.5,10.3,11.2,6.1,8.4,11,11.6$, 11.9, 5.2, 6.8, 8.9, 7.1, 10.8. APTP, Burr XII distribution by Burr[20], Kumaraswamy Rayleigh (KumR) by Rashwan [21], Beta Bur XII (Beta-BXII) by Paranaíba et al.[22], Weibull Lomax (W-L) by Tahir et al. [23]. Odd log-logistcWeibull (OLL-W) by Cruz et al. [24], and Exponentiated Generated Weibull (EG-W) by Cordeiro et al. [25] distributions are fitted to data. From Table 4, it is clear that the APTP distribution provides the overall best fit and therefore could be chosen as the most adequate model among the fitted models to second data. 
Table 4. Results of AIC and log-likelihood for APTP and other distributions for the data set.

\begin{tabular}{|l|l|c|c|c|}
\hline Model & ML Estimates of Parameters & AIC & BIC & $\ell$ \\
\hline APTP & $\hat{\alpha}=485.77, \hat{\beta}=1.03$ & 221.9 & 228.8 & 109.2 \\
\hline Pareto & $\hat{\alpha}=0.39$ & 285.9 & 287.4 & 142.0 \\
\hline Burr XII & $\hat{\lambda}=0.07, \hat{\theta}=5.61$ & 518.5 & 521.3 & 257.2 \\
\hline Kum-R & $\hat{\alpha}=1.49, \hat{\theta}=73.62, \hat{\lambda}=4.70, \hat{\beta}=0.19$ & 400.9 & 401.8 & 196.5 \\
\hline Beta-Burr XII & $\hat{\alpha}=37.30, \hat{\theta}=1.09, \hat{\lambda}=0.89, \hat{\beta}=3.84$ & 385.9 & 386.8 & 188.9 \\
\hline W-L & $\hat{\alpha}=3.94, \hat{\beta}=3.26, \hat{\lambda}=2.61, \hat{\theta}=0.26$ & 396.6 & 397.5 & 194.3 \\
\hline OLL-W & $\hat{\alpha}=28.15, \hat{\lambda}=0.08, \hat{\theta}=793.68$ & 387.5 & 389.4 & 190.8 \\
\hline EG-W & $\hat{\alpha}=0.19, \hat{\beta}=11.15, \hat{\lambda}=0.77, \hat{\theta}=0.38$ & 387.5 & 388.3 & 189.7 \\
\hline TLG-Burr XII & $\hat{\alpha}=6.29, \hat{\beta}=7.32, \hat{\lambda}=0.68, \hat{\theta}=1.81$ & 385.5 & 386.4 & 188.8 \\
\hline APE & $\hat{\alpha}=328.19, \hat{\beta}=1.64$ & 223.5 & 226.4 & 109.7 \\
\hline Weibull & $\hat{\beta}=1.76, \hat{\lambda}=0.06$ & 225.5 & 228.4 & 110.8 \\
\hline
\end{tabular}

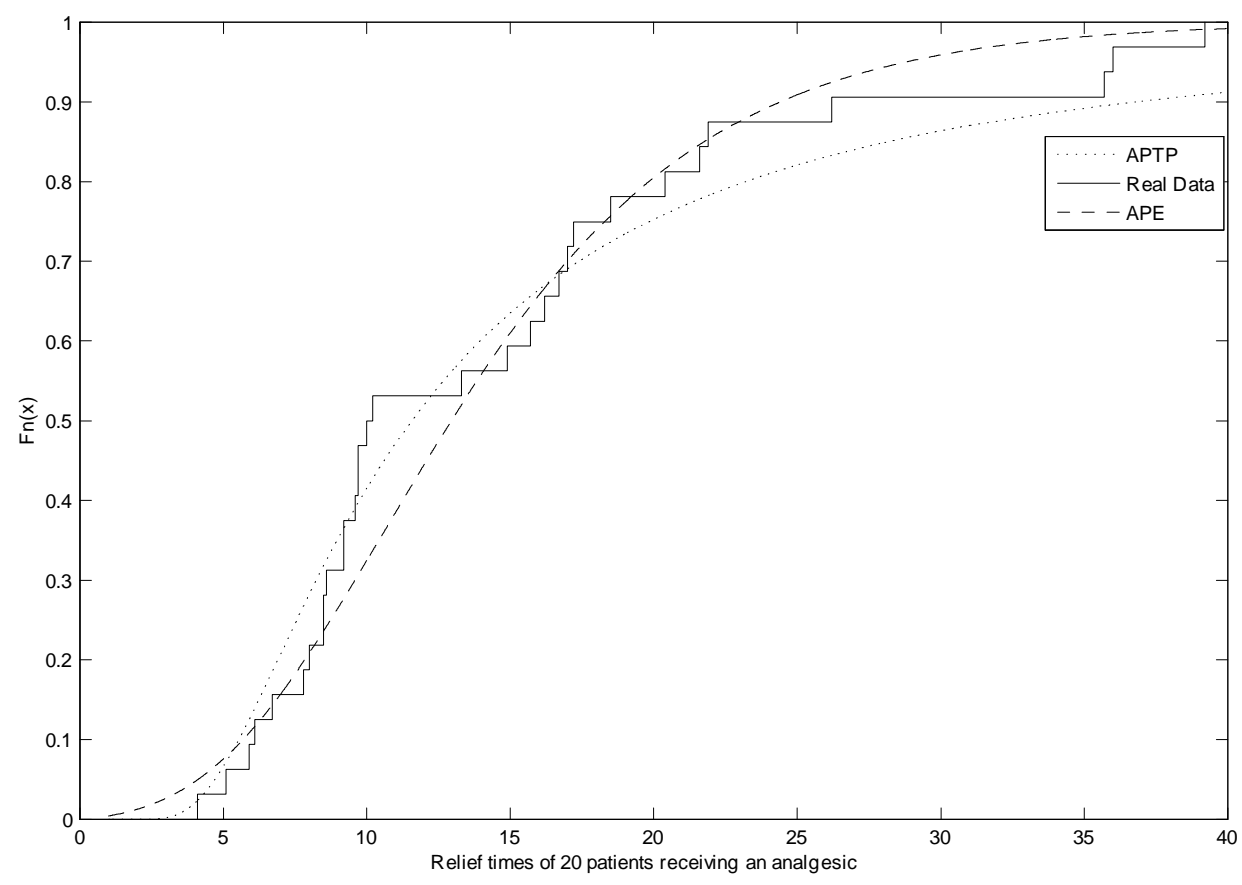

Figure 4. Empirical and some fitted distribution functions based on relief times data

\section{CONCLUSION}

In this study, APT family is considered with baseline Pareto distribution. ML and LS estimation are discussed for the parameters. An application of the APTP distribution to a real data set is given to demonstrate that this distribution can be used quite effectively to provide better fit than other available models.

\section{REFERENCES}

[1] Azzalini A., A class of distributions which includes the normal ones, Scandinavian journal of statistics, 24 (1985), 171-178. 
[2] Mudholkar G.S. and Srivastava D.K., Exponentiated weibull family for analyzing bathtub failurerate data, IEEE Transactions on Reliability, 42-2 (1993), 299-302.

[3] Gupta R.C., Gupta P.L. and Gupta R.D., Modeling failure time data by lehman alternatives, Communications in Statistics-Theory and Methods, 27-4 (1998), 887-904.

[4] Gupta R.D. and Kundu D., Exponentiated exponential family: an alternative to gamma and Weibull distributions, Biometrical Journal: Journal of Mathematical Methods in Biosciences, 43-1 (2001), 117-130.

[5] Marshall A.W. and Olkin I., A new method for adding a parameter to a family of distributions with application to the exponential and weibull families, Biometrika, 84-3 (1997), 641-652.

[6] Eugene N., Lee C. and Famoye F., Beta-normal distribution and its applications, Communications in Statistics-Theory and Methods, 31-4 (2002), 497-512.

[7] Alzaatreh A., Lee C. and Famoye F., A new method for generating families of continuous distributions, Metron, 71-1 (2013), 63-79.

[8] Mahdavi A. and Kundu D., A new method for generating distributions with an application to exponential distribution, Communications in Statistics - Theory and Methods, 46-13 (2017), 65436557.

[9] Lagarias J.C., Reeds J.A., Wright M.H. and Wright P.E., Convergence Properties of the NelderMead Simplex Method in Low Dimensions, SIAM Journal of Optimization, 9-1 (1998), 112-147.

[10] Feigl P. and Zelen M., Estimation of Exponential Survival Probabilities with Concomitant Information, Biometrics, 21-4 (1964), 826-838.

[11] Barreto-Souza W., Santos A.H.S. and Cordeiro G.M., The Beta generalized exponential distribution, Statist. Comput. Simul., 80 (2010), 159-172.

[12] Nadarajah S. and Kotz S., The Beta exponential distribution, Reliability Engrg. System Safety, 91 (2006), 689-697.

[13] Akinsete A., Famoye F. and Lee C. The Beta-Pareto distribution, Statistics, 42-6(2008), 547-563.

[14] Gupta R.D. and Kundu D., Generalized exponential distributions, Australian and New Zealand Journal of Statistics, 41-2 (1999), 173-188.

[15] Kus C, A new lifetime distribution, Comput. Statist. Data Anal., 51(2007), 4497-4509.

[16] Pescim R.R., Dem'etrio C.G.B., Cordeiro G.M., Ortega E.M.M. and Urbano M.R., The Beta generalized half-Normal distribution, Comput. Statist. Data Anal., 54 (2009), 945-957.

[17] Cooray K. and Ananda M.M.A., A generalization of the half-normal distribution wit applications to lifetime data, Comm. Statist. Theory Methods, 37 (2008), 1323-1337.

[18] Torabi H. and Montazeri N.H., The Gamma-Uniform distribution ans its applications, Kybernetika, 48-1 (2012), 16-30.

[19] Nassar M.M. abd Nada N.K., The beta generalized Pareto distribution, Journal of Statistics: Advances in Theory and Applications, 6 (2011), 1-17.

[20] Burr, I.W., Cumulative frequency functions, Annals of Mathematical Statistics, 13(1942), 215-232.

[21] Rashwan N.I., A note on Kumaraswamy exponentiated Rayleigh distributioni, Journal of Statistical Theory and Applications, 5 (2016), 286-295.

[22] Paranaíba P.F., Ortega E. M., Cordeiro G. M. and Pescim R.R., The beta Burr XII distribution with application to lifetime data, Computational Statistics and Data Analysis, 55-2 (2011), 1118-1136.

[23] Tahir, M.H., Cordeiro G. M., Mansoor M. and Zubair M., The Weibull-Lomax distribution: properties and applications, Hacettepe Journal of Mathematics and Statistics, 44-2 (2015), 461-480.

[24] Cruz J.N.D., Ortega E.M. and Cordeiro G.M., The log-odd log-logistic Weibull regression model: modelling, estimation, influence diagnostics and residual analysis, Journal of Statistical Computation and Simulation, 86-8 (2016), 1516-1538.

[25] Cordeiro G.M., Gomes A.E., da-Silva C.Q. and Ortega E.M., The beta exponentiated Weibull distribution, Journal of Statistical Computation and Simulation, 83-1 (2013), 114-138. 